\title{
OPERATING COST EFFICIENCY OF DIFFERENT SIZE SECTIONAL TITLE DEVELOPMENT SCHEMES
}

\author{
Merwe Oberholzer* \\ North-West University \\ Merwe.Oberholzer@nwu.ac.za \\ Gert van der Westhuizen" \\ North-West University \\ profgertvdwesthuizen@gmail.co \\ Christiaan Smit+ \\ North-West University \\ christiaans@autoacc-sa.co.za
}

September 2011

\begin{abstract}
The purpose of the study was to estimate the relative efficiency of different sizes of residential Sectional Title Development Schemes (STDSs) in order to minimise operating costs. Since area $\left(\mathrm{m}^{2}\right)$ and the number of units in an STDS were found to be equally important drivers of operating costs, data envelopment analysis was used to estimate the efficiencies of a sample of 113 STDSs where the two measures of size were used as output variables and six categories of operating costs were used as input variables. It is evident that smaller STDSs tend to be more efficient in minimising operating costs than larger STDSs. Furthermore, it is also evident that economies of scale generally do not exist. The main limitation was that the role of a categorised scale of basic housing (lower market) or the scale of luxurious housing (upper market) was not considered.
\end{abstract}

Keywords

Sectional title development schemes, data envelopment analysis, efficiency, operating costs

\footnotetext{
*Prof Merwe Oberholzer is professor in the Faculty of Economic and Management Sciences, North-West University, Potchefstroom, South Africa

\#Prof Gert van der Westhuizen is professor in the Faculty of Economic Sciences and Information Technology, North-West University, Vaal Triangle Campus, Vanderbijlpark, South Africa
}

+Mr Christiaan Smit is a master's student at the Faculty of Economic and Management Sciences, North-West University, Potchefstroom, South Africa 


\section{INTRODUCTION}

A Sectional Title Development Scheme (STDS) is a form of ownership where a number of people simultaneously own a part of the land on which a building or buildings are erected, and each individual owner owns a unit, like a house or apartment (Constas \& Bleijs, 2009:9). Each owner is responsible for a levy, which is based on the participation quota (area of a unit divided by the total area of the specific STDS) (Section 32 of the Sectional Titles Act 95 of 1986). This levy is used to cover operational costs, e.g. insurance, common property electricity, water, elevator maintenance, audit fees, management agency fees, salaries and wages, security, pool and maintenance expenses (Woudberg, 1999:12-15). STDSs provide significant benefits for owners, such as the creation of facilities that would not be affordable for a single owner, for example, security and the establishment of a management infrastructure to administer the common property.

This study investigated the degree to which the size of STDSs influences their efficiency in minimising their operating input cost. Since STDSs' operating costs are not readily available, this investigation will provide investors with more insight regarding the difference in relative operating costs of different sizes of STDSs. Other interest groups, such as STDS trustees, property management agencies and developers of STDSs can also benefit from this knowledge.

Several South African studies have been done on STDSs. Brand (1999) did a study on the tax aspects of sectional title, share block and time-share schemes. Schutte (1995) investigated the cost behaviour of sectional title schemes. Strydom (1997) did a study on the legal aspects of operating an STDS. Jonker (1988) studied different legal frameworks for retirement occupation. Uys (1990) did a study on proposals to improve the still unsatisfactory position of business owners under the Sectional Titles Act. Cloete (1982) did a study on the investment potential of residential STDSs. The gap in the literature is that previous research did not determine the degree to which the operating costs of STDSs are influenced by the size of the STDSs. Therefore, the research question of this study is: Does size matter with regard to STDSs minimising operating costs?

The purpose of the study is to estimate the relative efficiency of different sizes of residential STDSs in minimising operating costs. The central argument is that there should be an optimal size for an STDS, i.e. where the operating input costs in relation to the STDS' size are the lowest. A simple method of answering the research question would have been to divide the total costs of each STDS in a sample by the size of each STDS. This would indicate the relative difference in operating costs between different sizes of STDSs. The problem was to define the size of STDSs, since this study identified that both the area $\left(\right.$ in $\mathrm{m}^{2}$ ) and the number of individual units in STDSs are equally significant in generating the different operating costs items (TABLE 1 ). Therefore, both these measures of size should be taken into account. Data envelopment analysis (DEA) was used to estimate the efficiency (technical and scale) of different sizes of STDSs in minimising operating costs. DEA was selected because it lends itself to aggregate the performance into a single measure where multiple outputs (area and number of units) and multiple inputs (various operating cost items) are used (Coelli, Rao, O'Donnell \& Battese, 2005:6). Furthermore, it overcomes the problem of weighting when a number of input and output variables are used (Munksgaard, Wier, Lenzen \& Dey, 2005:169).

The organisation of the paper is as follows: section 2 provides the background of STDSs; section 3 explains the theory of DEA and states the hypothesis; the method of the study is explained in section 4, i.e. the data and sample and the DEA model; the results are exhibited in section 5 ; 
section 6 contains a discussion of the results and conclusions are drawn; and the study is summarised and the practical implication is discussed in section 7 .

\section{BACKGROUND}

This section focuses on the conceptual scope of the study, namely that the owners of STDSs enable the trustees to operate the STDSs effectively, by financing the different operating cost components through levies.

According to Maree (2001:1.1), the South African concept of property is based on the principles of Roman law. The Romans defined unmovable property with reference to a specific piece of land, measured only on a horizontal plan. All improvements to the land automatically became part of it. However, urbanisation in the $20^{\text {th }}$ century has forced landowners to build vertically to utilise the sky space.

The demand for urban housing increased and the result was that land became unaffordable. Apartments were the answer allowing for the construction of residential buildings to use spaces optimally.

Initially, it was not possible for residents to take ownership of their homes because property could only be divided on the horizontal level. The Sectional Titles Act (95 of 1986) assisted in making individual ownership possible in STDSs. All owners of units in an STDS form the body corporate. The moment a unit is registered in the owner's name, the owner becomes part of the body corporate. The body corporate has the ability to contract, sue and be sued (Section 36 of Sectional Titles Act). Trustees are elected at the STDS's Annual General Meeting as the legal representatives and they are responsible for the administration and management of the body corporate (Annexure 8, Section 4). The most important function of a body corporate is to create a fund to cover expenses (Article 37). Article 32 requires that the fund, which is financed from the levies contributed by all the owners, is based on the participation quota, which is rounded to four decimal places (Paddock, 2008:7-1). The participation quota is very important as it is used to calculate each owner's levy and to determine the weight of each owner's vote at meetings (Constas \& Bleijs, 2009:13).

\section{THEORY}

\subsection{Background of DEA}

To summarise the argument, area (in terms of $\mathrm{m}^{2}$ ) and the number of individual units in an STDS are generators of operating costs that include a number of cost items. What is needed is a measurement tool that can aggregate the performance of STDSs to minimise operating costs into a single estimate. DEA was selected to determine the relative operating efficiency of different sized STDSs in minimising operating costs. Since Charnes, Cooper and Rhodes (1978) applied this technique in multi-input multi-output production units, it has been widely applied to estimate the relative efficiency of decision-making units (DMUs) in a single factor, where the same inputs are used to produce the same outputs (Liu \& Wang, 2009:4936; Cook \& Seinford, 2009:2). DEA is a non-parametric linear programming technique that measures the relative efficiency of a comparative ratio of outputs to inputs for each DMU (Ray 2004:1; Avkiran, 1999:206). The main usefulness of DEA is that this methodology identifies the best practice of a 
set of comparable DMUs, which form an efficiency frontier that is used as a benchmark to estimate the level of inefficient units (Cook \& Seinford, 2009:1).

This study focuses on two kinds of efficiency, namely technical and scale efficiency. The efficiencies can be determined from an input-orientated (input minimisation) or outputorientated (output maximisation) point of view (Coelli et al., 2005:52 \& 57). A DMU is technically efficient if it produces a given set of outputs using the smallest possible number of inputs and it is scale efficient if it operates on a scale that maximises productivity (Avkiran, 1999:206-207, 211). Furthermore, analysts choose between using constant return to scale (CRS) or variable return to scale (VRS). The first implies a proportionate rise in outputs when inputs are increased, i.e. a DMU's efficiency is not influenced by the scale of operations (Avkiran, 1999:211). This is a significant assumption, since CRS may only be valid over a limited range and its use should be justified (Anderson, 1996). "VRS implies a disproportionate rise or fall in outputs when inputs are increased" (Avkiran, 1999:211), i.e. if a DMU grows in size, its efficiency will not stay constant and it will either rise or fall. Using CRS a DMU is automatically fully scale efficient. Using the VRS approach, the degree of scale efficiency can be estimated, i.e. where a DMU is too small in its scale operations, which falls within the increasing return to scale (irs) part of the production function, or a DMU is too large if it falls within the decreasing return to scale (drs) part of the production function. These inefficient DMUs can be improved by keeping the same input mix, but changing the size of operations (Coelli et al., 2005:58).

\subsection{Measuring technical efficiency}

In the case of a firm that produces $J>1$ outputs using $I>1$ inputs, total productivity can be measured as the ratio of a weighted sum of outputs to a weighted sum of inputs (i.e. the ratio of an output index to an input index). DEA can be thought of as a technique for choosing a set of $J+1$ weights for each firm in such a way that each firm's measured productivity is maximised (i.e. so each firm is cast in the best possible light). If there are $N$ firms, and if the production technology exhibits CRS, the DEA problem for firm $n$ is formulated as:

$$
\begin{aligned}
& \operatorname{Max}_{u_{n}, v_{n}} \frac{u_{n \prime y_{n}}}{v_{n \prime x_{n}}} \quad \text { (i.e. max. productivity } \frac{\text { output index }}{\text { input index }} \text { ) } \\
& \text { s.t. } \frac{u_{n} \prime y_{m}}{v_{n} \prime x_{m}} \leq 1 \text { for } m=1, \ldots, N \text { (boundary constraints) } \\
& \text { and } u_{n}, v_{n} \geq 0 \text { (non-negativity constraints) }
\end{aligned}
$$

where $y_{n}$ is the $J \times 1$ vector of observed outputs of firm $n, x_{n}$ is the $I \times 1$ vector of observed inputs, an $u_{n}$ and $v_{n}$ are unknown vectors of (non-negative) output and input weights. This form of the DEA problem is known as the ratio form.

There are two points to note concerning the ratio form of the DEA problem. Firstly, the boundary constraints serve to ensure that the maximised value of the objective function is no greater than one. More importantly, under this constraint it can be shown that the maximised value of the objective function is also a measure of the technical efficiency of firm $n$.. Secondly, there is an infinite number of sets of weights that will maximise the objective function. To identify a unique set of weights, analysts typically normalise or scale the weights so that the input index for firm $n$. is equal to one. Then the DEA problem becomes: 


$$
\begin{aligned}
& \operatorname{Max}_{n}, v_{n} \\
& \text { s.t. } u_{n}{ }^{\prime} y_{m}-v_{n}{ }^{\prime} y_{n} x_{m} \leq 0 \text { for } m=1, \ldots, N \\
& v_{n}{ }^{\prime} x_{n}=1 \text { (normalisation constraint) } \\
& u_{n}, v_{n} \geq 0
\end{aligned}
$$

This is a standard LP and is known as the multiplier form of the DEA problem. The maximised value of the objective function in (2) is the DEA estimate of the technical efficiency of firm $n$ (under CRS) and lies between zero and one.

One other form of the DEA problem is of interest. This form is obtained by invoking the theory of duality in linear programming, which states that any LP can be solved as either a maximisation or a minimisation problem. The minimisation problem corresponding to (2) is:

$$
\begin{aligned}
& \operatorname{Min}_{q_{n}} \theta_{n} \\
& \text { s.t. } Y \lambda_{n}-y_{n} \geq 0 \\
& \theta_{n} x_{n}-X \lambda_{n} \geq 0 \\
& \lambda_{n} \geq 0, \theta_{n} \geq 0
\end{aligned}
$$

Where $Y=\left(y_{1} \ldots, y_{N}\right)$ is a $J \times N$ matrix of observed outputs, $X=\left(x_{1} \ldots, x_{N}\right)$ is an $I \times N$ matrix of observed inputs, $\lambda_{n}$ is an unknown $N \times 1$ vector, and $\theta_{n}$ is an unknown scalar. This standard LP is known as the envelope form of the DEA problem. The envelope form is popular in empirical work because it typically involves fewer constraints than the multiplier form and may, therefore, be computationally easier to solve.

\subsection{Measuring scale efficiency}

Recall from 3.2 that scale efficiency can be estimated by dividing a CRS estimate of technical efficiency by a VRS estimate. The DEA problem (1) is underpinned by a CRS assumption, so the minimised value of the objective function in (3) can be regarded as a CRS estimate of technical efficiency. A VRS estimate is obtained as the minimised value of the objective function in the following LP:

$$
\begin{aligned}
& \underset{q_{n}, l_{n}}{\operatorname{Min}} \theta_{n} \\
& \text { s.t. } Y \lambda_{n}-y_{n} \geq 0 \\
& \theta_{n} x_{n}-X \lambda_{n} y_{n} \geq 0 \\
& j \lambda_{n}=1 \quad \text { (VRC constraint) } \\
& \lambda_{n} \geq 0, \theta_{n} \geq 0
\end{aligned}
$$


where $j$ is an $N \times 1$ vector of ones. The VRS problem (4) is identical to the CRS problem (3) except for the inclusion of the VRS constraint $j \lambda_{n}=1$. For details, see Coelli et al. (2005).

\subsection{Hypothesis}

This study sought the STDS size that is relatively the most efficient in minimising operating costs. Since this topic has not previously been investigated, it can be classified as an exploratory approach, i.e. it is a preliminary investigation into a relatively new area (Terre Blance, Durrheim \& Painter, 2008:45). The aim of this exploratory approach was to seek new insight into a phenomenon, i.e. an attempt to explain reasons for this phenomenon (Terre Blanche et al., 2008:45; Blumberg, Cooper \& Schindler, 2008:11). In assisting the establishment of a hypothesis, the principles of economies of scale were taken as a framework, i.e. the expectation is that the larger the size of an STDS, the more efficient it will be in minimising operating costs. Therefore, the null-hypothesis is as follows:

$\mathrm{H}_{0}$ : There is no positive relationship between the size of an STDS and the efficiency in minimising operating costs.

\section{METHODOLOGY}

\subsection{Data and sample}

Data for this study was taken from Angor Property Specialists (Pty) Ltd's database. A random sample of 100 STDSs was selected. Since the sample consists of relatively few STDSs with a floor area between 10000 and $25000 \mathrm{~m}^{2}$, another 13 STDSs (the unused STDSs in the database) were added by means of a convenient sample.

The operating costs for the study are the actual expenses of STDSs for the financial year that ended in 2010. Since year-end dates differ, the effect of inflation was neutralised by discounting all values to December 2010 using the consumer price index.

Electricity is charged to the owners according to each owner's usage, but since this electricity and electricity on common property are not separated in the data, it was not possible to calculate the electricity on common property. For this reason, common property electricity was excluded. Twenty-five of the 113 STDSs have separate water meters for each unit, while the remaining STDSs classified water as a common cost. To achieve data consistency, water was classified as a common cost for all STDSs. Garden and pool expenses are also not considered, since it is not necessarily a function of the size of the complex. To make the data more meaningful, the less significant cost items were grouped together. Non-municipality garbage removal (2.8\%), other expenses (1.2\%) and professional services $(1.0 \%)$ were grouped under the heading "Other". Cost of water (9.1\%) and sewerage (13.5\%) were also grouped together, because both are municipal services. Note that special projects are also excluded, because their appearance is usually on an ad hoc basis and of a capital nature since they are used for the improvement of the common property.

TABLE 1 exhibits the cost data used in the study. The weight of each cost item is given first, e.g. the largest cost item is security (24.5\%). The R-values are Pearson's correlation coefficients between each cost item (as independent variable $\mathrm{x}$ ) and firstly where the dependent variable ( $y$ ) is the total area of the STDS and secondly where the dependent variable is the number of units in 
the STDS. Although the correlation coefficient does not imply a cause-and-effect relationship, but is merely an observed statistical observation (Wegner, 2007:418), none of these dependent variables should be excluded from further analyses. The reason is that all the $p$-values related to all the correlation coefficients in TABL $\mathbf{l}$ are significant at a level of $1 \%$, where $p<\alpha=.01$ (two-tailed).

TABLE 1 also exhibits the descriptive statistics of the cost items (Rand values). The standard error indicates how the data differs from the total population if it is assumed that all the data of the population is normally distributed. The standard deviation and the range indicate that the data is widely spread around the mean. The positive kurtosis values imply that the curves of the cost items have high peaks and the positive skewness values imply that the 'tail' of the curves is to the right, which means the medians are higher than the means.

TABLE 1: Analysis of the cost data $(n=113)$

\begin{tabular}{lllllllll}
\hline Weight & & $\begin{array}{c}\text { Insur- } \\
\text { ance }\end{array}$ & $\begin{array}{c}\text { Mainte- } \\
\text { nance }\end{array}$ & Security & $\begin{array}{c}\text { Manage- } \\
\text { ment }\end{array}$ & $\begin{array}{c}\text { Sewer- } \\
\text { age \& } \\
\text { water }\end{array}$ & Other \\
\hline$R^{*}$ & 0.082 & 0.208 & 0.245 & 0.188 & 0.226 & 0.050 \\
$R^{*}$ & y=area & 0.756 & 0.653 & 0.780 & 0.806 & 0.833 & 0.736 \\
& y=units & 0.676 & 0.629 & 0.677 & 0.754 & 0.878 & 0.742 \\
Descriptive & Mean & 86881 & 221088 & 260466 & 200207 & 240391 & 53073 \\
Statistics & Std error & 8238 & 23893 & 19597 & 16577 & 17838 & 5816 \\
(Rand) & Std dev & 87568 & 253985 & 208314 & 176212 & 189617 & 61825 \\
& Kurtosis & 11.04 & 13.75 & 0.40 & 3.18 & 1.20 & 3.65 \\
& Skewness & 2.97 & 3.21 & 0.74 & 1.76 & 1.27 & 1.93 \\
& Range & 555711 & 1658787 & 897519 & 829731 & 886294 & 314034 \\
\hline
\end{tabular}

Source: Excel assimilation of Angor (Pty) Ltd's data

* Significant at $1 \%$ (two-tailed)

TABLE 2 exhibits the descriptive statistics of the two y variables, namely the number of units and the area $\left(\mathrm{m}^{2}\right)$ of STDSs. The smallest STDS, in terms of number of units, have eight units, while the largest has 389 units. The smallest STDS in terms of area is $704 \mathrm{~m}^{2}$ and the largest is $27579 \mathrm{~m}^{2}$.

Since the above-mentioned data is spread over a large range, it was for practical purposes, decided to divide it into two groups, namely the first group of 75 STDSs, with a range between eight and 100 units, and the second group of 38 STDSs with a range between 101 and 389 units. This provided information to compare the relative efficiency of small STDSs with the relative efficiency of large STDSs. 
TABLE 2: Descriptive statistics of the number of units and area of STDSs $(n=113)$

\begin{tabular}{lcc} 
& Units & Area $\left(\mathrm{m}^{2}\right)$ \\
\hline Mean & 95.05 & 8407 \\
Std error & 6.80 & 568 \\
Std dev & 72.28 & 6039 \\
Kurtosis & 3.63 & 1.31 \\
Skewness & 1.72 & 1.25 \\
Range & 381 & 26875 \\
Minimum & 8 & 704 \\
Maximum & 389 & 27579 \\
\hline
\end{tabular}

Source: Excel assimilation of Angor (Pty) Ltd's data

Since the above-mentioned data are spread over a large range, it was for practical purposes decided to divide it into two groups, namely the first group of 75 STDSs, with a range between eight and 100 units, and the second group of 38 STDSs with a range between 101 and 389 units. This provided information to compare the relative efficiency of the small STDSs with the relative efficiency of large STDSs.

\subsection{DEA model}

The successful application of the assessment of comparative efficiency of companies depends on the selection of appropriate input variables and output variables (Min, Min, Joo \& Kim, 2009:837). Unless managers are concerned that variables should be restricted because they are over-represented or under-represented, common practice allows the optimisation model to determine the weight for each variable (Avkiran, 1999:214). In this study, the two measures of size were used as output measures, where the input variables consist of six different operating cost items. This is to determine the role of size in the efficiency to minimise operating cost of STDSs. The reason for using six different cost categories is because different costs may behave differently with regard to size. This will provide more substance to the results because best practices for each cost category can be identified. The following model was specified:

Outputs: $\quad y_{1}=$ Area of STDS $\left(m^{2}\right) ; y_{2}=$ Number of units in STDS

Inputs: $\quad X_{1}=$ Security (Rand); $X_{2}=$ Sewerage and water (Rand); $X_{3}=$ Maintenance and repairs (Rand);

$X_{4}=$ Management $($ Rand $) ; X_{5}=$ Insurance $($ Rand $) ; X_{6}=0$ ther $($ Rand $)$

The aim of the model was threefold.

Firstly, it helped to estimate the technical efficiency (i.e. the relative efficiency of an STDS to use a mix of input costs to operate the output, namely the number of units and the total area of the STDS), which was then compared to the sizes (number of units and area) in order to determine the relationship between technical efficiency and size.

Secondly, it helped to estimate scale efficiency (i.e. to indicate whether or not the different sizes of STDSs achieved economies of scale). 
Thirdly, it helped to identify the number of times that an STDS is a peer (benchmark) to another. In other words, it determines how the different cost items of inefficient STDSs should be changed to operate on the efficiency frontier. The input-orientated approach was used, which examines the extent to which inputs can be reduced while maintaining output levels (Avkiran, 1999:211). Furthermore, the less restricted VRS approach was used (See 3.2 and 3.3 for the equations). Since estimating technical and scale efficiencies might have been complex calculations, the software package of Coelli (1996), which is purpose-built to solve this DEA problem, was used to generate estimates. (Note that other software packages could also be used to arrive to the same results.)

\section{RESULTS}

TABL 3 exhibits the relative efficiency estimates for small STDSs. Twenty-eight STDSs were fully technically efficient $(T \varepsilon)$, which include 19 STDSs that were both fully technically and fully scale efficient $(S E)$. Since an input-orientated approach was used, it means that these fully technically efficient STDSs used relatively less operating costs than their peers, but were of similar size. The average technical efficiency (76.4\%) implies that the inefficient STDSs can reduce, on average, their input costs by $23.6 \%$. Twenty-two (79\%) of the fully technically efficient STDSs appear in the area that is lower than the median (51 units), while only six (21\%) of the fully technically efficient STDSs appear in the area above the median. The average scale efficiency estimate is $72.0 \%$, which indicates that a large number of the STDSs is of the wrong size, implying that they are either too large or too small. Twenty STDSs (27\%) were fully scale efficient, while 50 STDSs (67\%) were operating at increasing returns to scale (irs) and five STDSs (7\%) were operating at decreasing return to scale (drs). Fourteen $(74 \%)$ of the fully scale efficient STDSs appear in the area that is lower than the median ( 51 units), while only five (26\%) of the fully scale efficient STDSs appear in the area above the median. $74 \%(67 \%+7 \%)$ of STDSs could improve their technical efficiency by changing the scale of their operations, namely to keep their input mix (six cost items) constant, but to lower them proportionally.

Although the CRS approach was not used (i.e. based on the assumption that STDSs are able to linearly scale their inputs and outputs without changing their efficiency), its value is that it helped to arrive at the conclusion that all these scale inefficient STDSs did not achieve economies of scale. Say, for example, an STDS can achieve economies of scale by using an input mix of operating costs to the amount of R100 000 with a size of 100 units and an area of 10 $000 \mathrm{~m}^{2}$. If the STDSs are operating at increasing returns to scale, they may for example require inputs to the amount of R50 000 where the size is only 10 units and an area of $1000 \mathrm{~m}^{2}$. On the opposite side, if the STDSs are operating at decreasing returns to scale, they may require, for example, operating costs to the amount of R300 000, where the size is only 200 units and an area of $20000 \mathrm{~m}^{2}$.

TABLE 4 exhibits the relative efficiency estimates for large STDSs. Eight STDSs were fully technically as well as fully scale efficient. The average technical efficiency estimate was $59.2 \%$, which implies that, on average, these inefficient STDSs can reduce their inputs by, on average, $40.8 \%$. There is no obvious difference between the number of fully technically and scale efficient STDSs on either side of the median $(151+157) / 2)$. The eight $(21 \%)$ STDSs that were fully scale efficient indicate that only eight STDSs were of the right size. Twenty-two (58\%) STDSs operated at increasing returns to scale (irs) and eight (21\%) STDSs operated at decreasing returns to 
scale (drs). $79 \%$ of STDSs could improve their scale efficiency by changing their scale of operations, either by scaling down or scaling up some operations.

TABLE 3: Relative efficiency estimates for small STDSs $(n=75)$

\begin{tabular}{|c|c|c|c|c|c|c|c|c|c|}
\hline $\begin{array}{l}\text { Number } \\
\text { of units }\end{array}$ & $\begin{array}{l}\text { Area } \\
\text { in } m^{2}\end{array}$ & $T \varepsilon$ & $S E$ & Return & $\begin{array}{l}\text { Number } \\
\text { of units }\end{array}$ & $\begin{array}{l}\text { Area } \\
\text { in } m^{2}\end{array}$ & $T \varepsilon$ & $S E$ & $\begin{array}{l}\text { Re- } \\
\text { turn }\end{array}$ \\
\hline 8 & 704 & 1.000 & 1.000 & - & 51 & 5120 & 0.753 & 0.222 & irs \\
\hline 11 & 1694 & 1.000 & 1.000 & - & 52 & 5458 & 0.496 & 0.724 & irs \\
\hline 12 & 1065 & 1.000 & 0.162 & irs & 54 & 3294 & 0.764 & 0.523 & irs \\
\hline 13 & 767 & 1.000 & 1.000 & - & 54 & 5073 & 0.747 & 0.130 & irs \\
\hline 16 & 736 & 1.000 & 1.000 & - & 55 & 7694 & 0.481 & 0.974 & irs \\
\hline 22 & 1738 & 1.000 & 1.000 & - & 56 & 4261 & 1.000 & 1.000 & - \\
\hline 26 & 2392 & 0.822 & 0.547 & irs & 57 & 6073 & 0.965 & 0.184 & irs \\
\hline 27 & 1686 & 0.776 & 0.968 & irs & 58 & 10089 & 0.517 & 0.160 & irs \\
\hline 27 & 2241 & 1.000 & 0.463 & irs & 60 & 5226 & 0.662 & 0.425 & irs \\
\hline 29 & 3219 & 1.000 & 0.543 & irs & 60 & 4272 & 0.691 & 0.518 & irs \\
\hline 30 & 2522 & 0.683 & 0.802 & irs & 67 & 6437 & 1.000 & 1.000 & - \\
\hline 31 & 3981 & 1.000 & 0.952 & drs & 68 & 5307 & 1.000 & 0.713 & irs \\
\hline 32 & 2289 & 0.696 & 0.405 & irs & 68 & 6708 & 0.514 & 0.995 & irs \\
\hline 32 & 2540 & 0.675 & 0.758 & irs & 68 & 4624 & 0.508 & 0.942 & irs \\
\hline 32 & 1528 & 1.000 & 1.000 & - & 69 & 6295 & 0.426 & 0.464 & irs \\
\hline 33 & 3231 & 1.000 & 0.557 & irs & 70 & 8966 & 1.000 & 1.000 & - \\
\hline 34 & 3214 & 1.000 & 0.943 & irs & 72 & 5074 & 0.365 & 0.122 & irs \\
\hline 35 & 2908 & 1.000 & 1.000 & - & 73 & 9865 & 0.579 & 0.953 & drs \\
\hline 35 & 4136 & 0.828 & 0.236 & irs & 75 & 5793 & 0.582 & 0.999 & - \\
\hline 36 & 5049 & 1.000 & 0.104 & irs & 76 & 5727 & 0.634 & 0.982 & irs \\
\hline 36 & 3182 & 0.955 & 0.295 & irs & 80 & 5570 & 0.443 & 0.857 & irs \\
\hline 38 & 5674 & 1.000 & 1.000 & - & 80 & 7392 & 0.460 & 0.645 & irs \\
\hline 38 & 2355 & 0.850 & 0.581 & irs & 82 & 6621 & 0.596 & 0.921 & irs \\
\hline 38 & 2939 & 1.000 & 1.000 & - & 83 & 5644 & 1.000 & 1.000 & - \\
\hline 38 & 2850 & 1.000 & 1.000 & - & 84 & 5880 & 0.537 & 0.981 & drs \\
\hline 40 & 4000 & 1.000 & 1.000 & - & 86 & 7014 & 0.405 & 0.082 & irs \\
\hline 43 & 4698 & 0.857 & 0.974 & irs & 86 & 9074 & 0.434 & 0.156 & irs \\
\hline 44 & 4722 & 0.718 & 0.991 & irs & 87 & 8767 & 0.413 & 0.997 & irs \\
\hline 44 & 3340 & 1.000 & 1.000 & - & 90 & 10371 & 0.549 & 0.709 & irs \\
\hline 44 & 3624 & 1.000 & 1.000 & - & 92 & 9264 & 0.317 & 0.456 & irs \\
\hline 44 & 4510 & 0.668 & 0.802 & irs & 93 & 8321 & 0.388 & 0.491 & irs \\
\hline 45 & 3459 & 0.541 & 0.647 & irs & 93 & 8557 & 0.632 & 0.868 & irs \\
\hline
\end{tabular}


Oberholzer, Van der Westhuizen \& Smit

\begin{tabular}{lcccc|ccccc}
\hline $\begin{array}{l}\text { Number } \\
\text { of units }\end{array}$ & $\begin{array}{c}\text { Area } \\
\text { in } m^{2}\end{array}$ & $T \varepsilon$ & $S E$ & Return & $\begin{array}{c}\text { Number } \\
\text { of units }\end{array}$ & $\begin{array}{c}\text { Area } \\
\text { in } m^{2}\end{array}$ & TE & $S E$ & $\begin{array}{c}\text { Re- } \\
\text { turn }\end{array}$ \\
\hline 46 & 2744 & 1.000 & 1.000 & - & 95 & 8163 & 0.580 & 0.262 & irs \\
49 & 6664 & 0.598 & 0.950 & irs & 96 & 7638 & 0.994 & 0.972 & drs \\
50 & 4268 & 1.000 & 0.846 & irs & 97 & 6962 & 0.797 & 0.859 & drs \\
50 & 7642 & 0.900 & 0.897 & irs & 98 & 13341 & 0.304 & 0.634 & irs \\
50 & 3300 & 0.517 & 0.477 & irs & 100 & 8040 & 0.671 & 0.200 & irs \\
& & & & & 100 & 10927 & 1.000 & 1.000 & - \\
\hline Mean & 0.764 & 0.720 & & & & & & \\
Min & 0.304 & 0.082 & & & & & & & \\
Max & 1.000 & 1.000 & & & & & &
\end{tabular}

Source: Angor (Pty) Ltd's data assimilated by software of Coelli (1996)

TABLE 4: Relative efficiency estimates for large STDSs $(n=75)$

\begin{tabular}{lcccc|ccccc}
\hline $\begin{array}{l}\text { Number } \\
\text { of units }\end{array}$ & $\begin{array}{c}\text { Area } \\
\text { in } m^{2}\end{array}$ & TE & $S E$ & Return & $\begin{array}{c}\text { Number } \\
\text { of units }\end{array}$ & $\begin{array}{c}\text { Area } \\
\text { in } m^{2}\end{array}$ & TE & $S E$ & $\begin{array}{c}\text { Re- } \\
\text { turn }\end{array}$ \\
\hline 101 & 10873 & 0.983 & 0.782 & drs & 157 & 14424 & 0.321 & 0.860 & irs \\
102 & 7628 & 0.447 & 0.961 & irs & 162 & 16893 & 0.990 & 0.793 & drs \\
103 & 12687 & 0.749 & 0.994 & irs & 168 & 11369 & 0.365 & 0.699 & irs \\
104 & 9238 & 0.351 & 0.406 & irs & 172 & 10148 & 0.370 & 0.294 & irs \\
104 & 6836 & 1.000 & 1.000 & - & 175 & 13915 & 0.656 & 0.901 & drs \\
105 & 19981 & 1.000 & 0.473 & drs & 177 & 15599 & 0.407 & 1.000 & - \\
108 & 16162 & 0.672 & 0.609 & irs & 178 & 26349 & 0.319 & 0.793 & irs \\
118 & 6490 & 1.000 & 1.000 & - & 179 & 15640 & 0.359 & 0.988 & drs \\
120 & 12218 & 0.269 & 0.431 & irs & 181 & 18949 & 1.000 & 1.000 & - \\
126 & 10914 & 0.882 & 0.948 & drs & 183 & 14409 & 0.499 & 0.633 & irs \\
135 & 8581 & 0.632 & 0.863 & irs & 184 & 10069 & 0.380 & 0.144 & irs \\
140 & 11588 & 0.372 & 0.989 & irs & 191 & 19063 & 0.441 & 0.161 & irs \\
143 & 11051 & 0.330 & 0.126 & irs & 221 & 15891 & 1.000 & 1.000 & - \\
144 & 8308 & 0.619 & 0.526 & irs & 225 & 17949 & 0.440 & 0.871 & drs \\
144 & 12761 & 1.000 & 1.000 & - & 278 & 19229 & 0.254 & 0.488 & irs \\
148 & 12617 & 0.446 & 0.870 & drs & 302 & 25033 & 0.272 & 0.132 & irs \\
150 & 14856 & 1.000 & 1.000 & - & 335 & 27202 & 0.132 & 0.582 & irs \\
150 & 9727 & 0.935 & 0.999 & irs & 345 & 27579 & 0.318 & 0.967 & irs \\
151 & 19349 & 0.297 & 0.791 & irs & 389 & 21862 & 1.000 & 1.000 & - \\
\hline Mean & & 0.592 & 0.739 & & & & & &
\end{tabular}




\begin{tabular}{|c|c|c|c|c|c|c|c|c|c|}
\hline $\begin{array}{l}\text { Number } \\
\text { of units }\end{array}$ & $\begin{array}{l}\text { Area } \\
\text { in } m^{2}\end{array}$ & $T \varepsilon$ & $S \varepsilon$ & Return & $\begin{array}{l}\text { Number } \\
\text { of units }\end{array}$ & $\begin{array}{l}\text { Area } \\
\text { in } m^{2}\end{array}$ & $T \varepsilon$ & $S \varepsilon$ & $\begin{array}{l}\text { Re- } \\
\text { turn }\end{array}$ \\
\hline Min & & 0.132 & 0.126 & & & & & & \\
\hline $\operatorname{Max}$ & & 1.000 & 1.000 & & & & & & \\
\hline
\end{tabular}

Source: Angor (Pty) Ltd's data assimilated by software of Coelli (1996)

TABLE 5: Peer count for STDSs

\begin{tabular}{ccc|ccc}
\hline Number of units & Area in $m^{2}$ & Peer count & Number of units & Area in $m^{2}$ & Peer count \\
\hline 8 & 704 & 71 & 44 & 3624 & 41 \\
11 & 1694 & 7 & 46 & 2744 & 26 \\
12 & 1065 & 15 & 50 & 4268 & 31 \\
13 & 767 & 2 & 67 & 6437 & 2 \\
16 & 736 & 7 & 68 & 5307 & 6 \\
22 & 1738 & 55 & 70 & 8966 & 23 \\
27 & 2241 & 18 & 83 & 5644 & 20 \\
31 & 3981 & 8 & 100 & 10927 & 1 \\
33 & 3231 & 2 & 104 & 6836 & 5 \\
34 & 3214 & 5 & 221 & 15891 & 7 \\
38 & 2939 & 3 & 389 & 21862 & 2 \\
44 & 3340 & 38 & & & \\
\hline
\end{tabular}

Source: Angor (Pty) Ltd's data assimilated by software of Coelli (1996)

TABLE $\mathbf{5}$ exhibits the peer count for the STDSs, which is the number of times an STDS is a peer (benchmark) for another. Twenty of the 75 (27\%) small STDSs act as benchmarks for other small STDSs. These 20 act 381 times as benchmarks to the remaining 55. The value of using six input cost categories in the DEA model provides more substance to the results, namely that different cost items of an inefficient STDS can be separately benchmarked to best practices. Note that more than one of the efficient STDSs may act as a peer to a single inefficient STDS. Fifteen (75\%) of the 20 lie below the median ( 51 units), while five (25\%) lie above the median. Only three of the 38 (8\%) large STDSs act 14 times as benchmarks for other large STDSs.

TABL $\varepsilon$ exhibits the correlation coefficient between the technical efficiency and the number of units in small STDSs, and technical efficiency and the area of small STDSs. The whole process was repeated with regard to large STDSs. The only significant relationships are between the technical efficiency of small STDSs and both the number of units and the area, which implies that the nullhypothesis should be rejected at a significance level of $1 \%$, where $\rho<\alpha=.01$ (two-tailed).

\section{DISCUSSION AND CONCLUSION}

STDSs vary in size as indicated by the number of units and size of the area. This study has shown that investors and other interested parties should be aware that there is in some cases (and in 
some cases not) a significant relationship between the different sizes of STDSs and their technical efficiencies. Scale efficiencies and also the peer counts differ among the different groups.

TABLE 6: Correlation coefficient ( $r$ ) and p-values

\begin{tabular}{cccc}
\hline Small STDSs & $\begin{array}{c}\text { Correlation } \\
\text { coefficient }\end{array}$ & p-value \\
\hline TE & No. of units & $(0.587)$ & $<0.001^{\star}$ \\
Large STDSs & Area $\left(\mathrm{m}^{2}\right)$ & $(0.556)$ & $<0.001^{\star}$ \\
$T \varepsilon$ & & & \\
& No. of units & $(0.261)$ & 0.113 \\
& Area $\left(\mathrm{m}^{2}\right)$ & $(0.265)$ & 0.108 \\
\hline
\end{tabular}

\section{Source: Authors'calculations}

* Significant at $1 \%$ (two-tailed)

Small STDSs and technical efficiency: According to the statistical test performed, a significant negative relationship was found between technical efficiency and firstly, the number of units, and secondly, area, which implies that the larger the number of units (and/or area) of these STDSs, the lower their technical efficiencies are. This negative relationship implies that economies of scale do not favour larger STDSs. In fact, the opposite pertains, because smaller STDSs are relatively more efficient in minimising operating costs. This is supported by the finding that $79 \%$ of the STDSs in this group smaller than the median (51 units) are fully technically efficient, while only $21 \%$ of the STDSs larger than the median are fully technically efficient. A possible reason is that the smaller STDSs may tend to operate at the lower end of the market with the aim of providing cheaper basic housing and the larger STDSs may tend to operate at the upper end of the market with the aim of providing relatively more expensive luxurious housing. Referring to the research question, the study concludes that from a costing point of view, size does matter, because the smaller STDSs are more efficient in minimising their operating costs.

Large STDSs and technical efficiency: The study found no significant relationship between the technical efficiency and firstly, the number of units, and secondly, area, which implies that the size of these STDSs is independent of their technical efficiencies. Therefore, no economies of scale exist for this group. A possible reason is that this group consists of a wide spread of STDSs that range from upper-market (expensive luxurious housing) to lower market (cheaper basic housing), where the former is more expensive to operate relative to the latter. With regard to the large STDSs, the study concludes that from a costing point of view, size does not matter, because it does not influence the efficiency in minimising operating costs.

Small STDSs and scale efficiency: Twenty STDSs (27\%) were fully scale efficient, which indicates that only they were of the right size. From the input-orientated point of view, they operate at a relatively smaller scale than their peers, but they have the same outputs (sizes). The majority of STDSs in this group, namely 50 STDSs (67\%), were operating at increasing returns to scale (irs) and only five STDSs (7\%) were operating at decreasing returns to scale (drs), which implies that the majority were operating at a scale that was too small and the latter five were operating at a scale that was too large. Since $14(74 \%)$ of the fully scale efficient STDSs appear in the area that is lower than the median (51 units), and while only five (26\%) of the fully scale efficient STDSs 
appear in the area above the median, the conclusion is drawn that there is some evidence that size matters with regard to this group, i.e. the smaller STDSs tend to be more fully scale efficient than the larger STDSs.

Large STDSs and scale efficiency: The eight (21\%) STDSs that were fully scale efficient indicate that only they were of the right size. From the input-orientated point of view, they operate at a relatively smaller scale than their peers, but they have the same outputs (sizes). Twenty-two (58\%) STDSs were operating at increasing returns to scale (irs) and eight (21\%) were operating at decreasing returns to scale (drs), which implies that the majority in this group were operating at a scale that was too small and the latter eight were operating at a scale that was too large. The study concludes that size does not matter with regard to this group of STDSs, since there is no obvious difference between the number of fully scale efficient STDSs on either side of the median $((151+157) / 2)$.

Peers: The above-mentioned conclusions are supported by focusing on the peer counts. Twenty of the 75 small STDSs act as benchmarks for other small STDSs. Fifteen (75\%) of the 20 lie below the median ( 51 units), while five (25\%) lie above the median. It is evident that the smaller units in this group tend to be more efficient than the larger units, because the smaller STDSs are more likely to serve as benchmarks for the inefficient STDSs. Since only three of the 38 large STDSs act as benchmarks for other large STDSs, no trend (relationship) with regard to size could be determined.

Large STDSs versus small STDSs: The small STDS group (76.4\%) is on average more technically efficient than the large STDS group (59.2\%), and the small STDSs (27\%) act more frequently as peers than is the case with the large STDSs ( $8 \%)$. There is only a negligible difference between the average scale efficiency of small STDSs (72\%) and the large STDSs (73.9\%). Consequently, the conclusion is drawn that size does matter, because small STDSs tend to be more efficient than the large STDSs.

\section{SUMMARY AND PRACTICAL IMPLICATIONS}

The purpose of the paper was to use DEA to estimate the relative efficiency of different sizes of residential STDSs in order to minimise operating costs. For this purpose, an input-orientated DEA was used to estimate the technical efficiency of the STDSs in the sample. The strength of the linear association between the technical efficiency and the different measures of size was determined. Since the VRS approach was used, it was also possible to estimate the scale efficiency of STDSs. The number of times that STDSs served as peers was also determined. To improve to comparability of the information, STDSs were grouped into two categories, i.e. small STDSs with 100 or fewer units and large STDSs with more than 100 units. The hypothesis to be tested was that there is no positive relationship between the size of an STDS and the efficiency in minimising operating costs.

The study concluded with regard to small STDSs that size does matter, because the smaller STDSs in this group are relatively more efficient in minimising their operating costs, they achieve economies of scale more easily and they act more frequently as peers than the larger STDSs in this group do. Secondly, with regard to the large STDSs, the study concluded that size does not matter, because there is no relationship between size and the efficiency in minimising operating costs, the appearance of full scale efficiency is haphazardly spread and too few STDSs act as peers to find any trends. In the comparison between the small STDS group and the large STDS 
group, the study concluded that size does matter, because small STDSs tend to be more efficient than the large STDSs.

The contribution of this study is that it is evident that STDS size generally does matter, i.e. smaller STDSs tend to be more efficient in minimising operating costs than larger STDSs. Furthermore, it is also evident that economies of scale generally do not exist with regard to residential STDSs. In fact, the opposite is to some extent true. Therefore, the optimal STDS size seems to be schemes with fewer than approximately 50 units and $5000 \mathrm{~m}^{2}$. It is important that investors and other interested parties note that the aim of an STDS (lower versus upper market) would also play an important role in the efficiency to minimise operating costs. Since the operating costs of STDSs are not readily available, the practical implication is that investors now know the role of STDSs' sizes on their efficiency in minimising operating costs, but the aim of catering for different markets (lower/ upper) should also be considered.

This exploratory study is of value because it is the first to use DEA to investigate the relationship between efficiency in minimising operating costs and the size of residential STDSs. There are some limitations. The first is that the investments and/ or expenditure in special projects, and the expenditure in common electricity, garden and swimming pool, were excluded from the cost analysis. The data used for this study does not provide substance with regard to a categorised scale of basic housing (lower market) or luxurious housing (upper market). The principle in practice is 'you get what you pay for', referring to owners of units in STDSs paying levies to finance operating costs. This is because owners decide on a level between the extremes of basic and luxurious housing regarding expenditure on several aspects, e.g. security, maintenance, repairs. Therefore, where significant negative relationships were found (between small STDSs and number of units and area), this study cannot pinpoint exactly which part is the contribution of size and which part is the contribution of the level between lower/ upper markets. Further research should be done to investigate these aspects.

\section{LIST OF REFERENCES}

Anderson, T. (1996). A data envelopment analysis (DEA) homepage. [Online] Available: http://www.emp.pdx.edu.dea/homedea.html/. (Accessed 10 February 2010).

Avkiran, N. (1999). Application reference for data envelopment analysis in branch banking: Helping the novice researcher. International Journal of Bank Marketing, 17(5), pp. 206-220.

Blumberg, B., Cooper, D.R. \& Schindler, P.S. (2008). Business research methods, $2^{\text {nd }}$ European edition. London: McGraw-Hill.

Brand, A. (1999). Die belastinghantering van deeltite/-, aandeleblok-, en eiendomstyd-deelskemas [The tax operation of sectional title-, share-block- and time-sharing schemes]. Unpublished MCom dissertation. Johannesburg: Randse Afrikaanse Universiteit.

Charnes, A., Cooper, W.W. \& Rhodes, \&. (1978). Measuring efficiency of decision-making units. European Journal of Operations Research, 2, pp. 429-444.

Cloete, C.E. (1982). Die beleggingspotensiaal van residensiële deeltitelontwikkelings in die oostelike voorstede van Pretoria [The investment potential of residential sectional title schemes in the eastern suburbs of Pretoria]. Unpublished MBL dissertation. Pretoria: University of South Africa. 
Coelli, T. (1996). A Guide to DEAP Version 2.1, A Data Envelopment Analysis (Computer) Program. (CEPA Working Paper 96/07). Armidale: Department of Econometrics, University of New England.

Coelli, T., Rao, D.S.P., O’Donnell, C.J. \& Battese, G.E. (2005). An introduction to efficiency and productivity analysis. New York: Springer.

Constas, M. \& Bleijs, K. (2009). Demystifying sectional title. South Africa: BBM Publishing.

Cook, W.D. \& Seinford, L.M. (2009). Data envelopment analysis (DEA) Thirty years on. European Journal of Operating Research, 192, pp. 1-17.

Liu, S-T. \& Wang, R-T. (2009). Efficiency measures of PCB manufacturing firms using relational twostage data envelopment analysis. Expert Systems with Applications, 36, pp. 4935-4939.

Jonker, M.A. (1988). Deeltitel-, aandeleblok-en okkupasieskemas as juridiese raamwerke vir aftreeoorde [Sectional title-, share-block- and occupation schemes for retirement centres]. Unpublished LLM dissertation. Johannesburg: Randse Afrikaanse Universiteit.

Maree, T. (2001). Kits deeltitel oplossings [Instant sectional title solutions]. Stellenbosch: MCS Publications.

Min, H., Min, H., Joo, S.J. \& Kim, J. (2009). Evaluating the financial performance of Korean luxury hotels using data envelopment analysis. The Service Industries Journal, 29(6), pp. 835-845.

Munksgaard, J., Wier, M., Lenzen, M. \& Dey, C. (2005). Using input-output analysis to measure the environmental pressure of usage of different spatial levels. Journal of Industrial Ecology, 9(1-2), pp. 169-185.

Paddock, G.J. (2008). Sectional title survival manual. Cape Town: Paddocks Publishing.

Ray, S.C. (2004). Data envelopment analysis: Theory and techniques for economics and operational research. Cambridge: Cambridge University Press.

Schutte, M. (1995). Kostegedrag en skeiding aan die hand van bepaling van heffingskoste by'n deeltitelkompleks [Cost behaviour and separation for estimating levies for a sectional title scheme]. Unpublished MCom dissertation. Pretoria: Vista University.

Sectional Titles Act. See South Africa (2002).

South Africa. (2002). Sectional Titles Act 95 of 1986. Durban: Butterworths.

Strydom, J.J. (1997). Regsaspekte van die bestuur van 'n deeltitelskema [Legal aspects of the management of a sectional title scheme]. Unpublished LLD thesis. Stellenbosch: Stellenbosch University.

Terre Blance, M., Durrheim, K. \& Painter, D. (eds.) (2008). Research in Practice: Applied methods for social sciences. Cape Town: University of Cape Town Press.

Uys, M. (1990). Voorstelle ter verbetering van die steeds onbevredigende posisie van sakedeeleienaars onder die Wet op Deeltitels, 1986 [Suggestions for improving the still unsatisfied position of business owners under the Act on Sectional Titles, 1986]. Unpublished LLM dissertation. Stellenbosch: Stellenbosch University.

Wegner, T. (2007). Applied Business Statistics. Cape Town: Juta.

Woudberg, T. (1999). Basic sectional title book one, $2^{\text {nd }}$ edition. Durban: Butterworths. 